\title{
Dynamic Support Stiffness of Motorized Spindle Bearings under High-speed Rotation
}

\section{Shengli Tian ( $\nabla 1163671455 @ q q . c o m$ )}

Chongqing University https://orcid.org/0000-0003-4078-7058

\section{Xingxin Zhao}

Chongqing Changjiang Bearing Co., Ltd., Chongqing 401336, China

\section{Shaojiang Dong}

Chongqing Key Laboratory of Manufacturing Equipment Mechanism Design and Control, Chongqing Technology and Business University, Chongqing 400067, China

\section{Research Article}

Keywords: High-speed motorized spindle, bearings, high-speed loading, dynamic support stiffness

Posted Date: March 22nd, 2021

DOl: https://doi.org/10.21203/rs.3.rs-258772/v1

License: (c) (i) This work is licensed under a Creative Commons Attribution 4.0 International License. Read Full License 


\title{
Dynamic Support Stiffness of Motorized Spindle Bearings under High-speed Rotation
}

\author{
TIAN Shengli ${ }^{1,2,3^{*}}$ ZHAO Xingxin ${ }^{2}$ DONG Shaojiang ${ }^{3}$ \\ (1. School of Mechantronics and Vehicle Engineering, Chongqing Jiaotong University, Chongqing 400074, China; \\ 2. Chongqing Changiiang Bearing Co., Ltd., Chongqing 401336, China; \\ 3. Chongqing Key Laboratory of Manufacturing Equipment Mechanism Design and Control, Chongqing \\ Technology and Business University, Chongqing 400067, China)
}

\begin{abstract}
The rotor operating stiffness of high-speed motorized spindles (HSMSs) is key to machining accuracy. Because HSMSs are difficult to load due to their high speeds, a contact loading device was developed to test rotor operating stiffness. The dynamic support stiffness of the front/rear bearings (DSSB) is the main factor affecting the rotor operating stiffness. Two novel experimental schemes for measuring the DSSB are proposed: 1) indirect measurement - by analysing deformation displacements at two points on the external loading rod of the HSMS, and 2) direct measurement—by eddy current sensors installed near the front/rear bearings. Based on the experimental device and two experimental schemes, the influences of working-condition parameters on the DSSB were tested. The results show that the proposed experimental device and two experimental schemes can effectively and accurately measure rotor operating stiffness and DSSB at speeds of up to $30,000 \mathrm{rpm}$. However, because the tapered connection gap between the loading rod and rotor increases the measured deformation displacement, the DSSB measured by the indirect measurement scheme was relatively small. The DSSB decreases with speed and increases with radial force and working temperature. This study provides a new experimental basis for the quality inspection of finished HSMSs and the verification of theoretical bearing stiffness models.
\end{abstract}

Keywords: High-speed motorized spindle, bearings, high-speed loading, dynamic support stiffness

\section{Introduction}

Because of its high efficiency, high precision and low energy consumption, high-speed machining technology has become a development trend in modern manufacturing technology ${ }^{1}$. A high-speed motorized spindle (HSMS) is the basis for high-speed machining technology ${ }^{1}$. The development of higher speeds and power has meant that the dynamic performance of HSMS has stricter requirements, especially in terms of rotor operating stiffness, which affects machining accuracy, reliability and production efficiency. The rotor operating stiffness of HSMS mainly depends on the dynamic support stiffness of the front/rear bearings (DSSB). However, due to centrifugal force and other inertial effects, the DSSB at high speed changes significantly compared with that at low speed. This directly affects the corresponding dynamic performance of bearing-rotor systems ${ }^{2}$. Research on experimentally measuring the rotor operating stiffness and DSSB is key to improving the anti-deformation ability of HSMS at high speeds.

The rotor operating stiffness of the HSMS in the rotating state can accurately reflect its anti-deformation 
ability in the actual working state. When measuring the rotor operating stiffness or DSSB, the HSMS must first be dynamically loaded. However, due to their structural features and high speeds, HSMSs are difficult to dynamically load. Existing loading methods can be categorised into contact loading and non-contact loading. Contact loading makes the inner ring of a rolling bearing rotate with the rotor of the HSMS, and then loads the stationary outer ring of the bearing to achieve loading of the rotor. For example, CHAO et al. ${ }^{3}$ designed an HSMS reliability test platform that uses an electro-hydraulic servo system to load the outer ring of the bearing. ALBRECHT et al. ${ }^{4}$ and OZTURK et al. ${ }^{5}$ used impact hammering on the outer rings of bearings. Contact loading is unsuitable for high-speed and long-term loading of HSMSs due to serious temperature increases and the wearing of rolling bearings at high speeds. Non-contact loading mainly includes electromagnetic loading and hydrostatic gas film loading. WANG et al. ${ }^{6}$ and MATSUBARA et al. ${ }^{7}$ designed an electromagnetic loading device, while FENG et al. ${ }^{8}$ presented a hydrostatic gas film loading device to measure the stiffness of HSMSs. However, electromagnetic loading tends to induce eddy currents, which cause the temperature of the HSMS to rise. In addition, the direction of the induced eddy currents is opposite to that of the electromagnetic field, so the higher the rotating speed, the lower the electromagnetic loading force. With hydrostatic gas film loading, the air gap must be controlled at about ten micrometres, which imposes strict requirements on the machining accuracy and installation accuracy of related parts. Additionally, gap adjustment is difficult in non-contact loading and the load is small and eccentric. In summary, HSMS dynamic loading methods require improvement.

Loading methods exist to measure the rotor operating stiffness of HSMS; however, there are relatively few studies on the direct and quantitative measurement of the DSSB of HSMS. At present, research on the DSSB is mainly based on the theoretical analysis of quasi-static ${ }^{9}$ or quasi-dynamic ${ }^{10}$ models of bearings; or uses rotor dynamics theory to analyse the modal characteristics of bearing-rotor systems ${ }^{11}$. Experimental methods mainly measure the modal characteristics (critical speed or natural frequency, etc.) of the bearing-rotor system to indirectly and qualitatively analyse the $\operatorname{DSSB}^{12,13}$. Sometimes, the above-mentioned contact loading method is used to measure the dynamic support stiffness of an external bearing driven by an HSMS. For example, LIN and JIANG ${ }^{14}$ used the contact loading method to measure the dynamic support stiffness of tandem-duplex angular-contact ball bearings driven by an HSMS. There is a lack of experimental methods that can quantitatively measure the DSSB of an HSMS under actual working conditions. This is essential for the verification of bearing stiffness models and HSMS dynamic performance detection.

By examining the problem of high-speed dynamic loading, this paper designed a method of applying load by contacting the outer ring of the rolling bearing with the rotor of the HSMS. This can be used for the stiffness test of the HSMS when the speed is as high as 30,000 rpm. To examine the problem of testing the DSSB, an experimental scheme was proposed to indirectly measure the DSSB by analyzing the deformation displacement of two points on the external loading rod of the HSMS. A special HSMS with eddy current sensors installed near the front and rear bearings was designed, which could directly and accurately measure the DSSB and verify the previous 
experimental scheme. A highly versatile stiffness test system of HSMS was built. The experiments measured the influence of radial force, speed and working temperature on the DSSB, and verified the validity and correctness of the stiffness test system and the two experimental schemes for the DSSB. This provides a simple and effective test system for the dynamic performance research and quality inspection of the finished HSMS, and provides experimental verification schemes for the bearing stiffness model.

\section{Measurement methods of the DSSB}

\subsection{Experimental HSMS and its equivalent model}

The structure of a specially designed HSMS is shown in Figure 1. The main feature of this HSMS is that mounting holes (where eddy current sensors can be installed on the housing near the front and rear bearing positions) are reserved to measure the deformation displacement of the rotor inside the HSMS. Temperature sensors (PT100) are installed on the front and rear bearing seats. The temperature sensor is close to the outer rings of the front and rear bearings and can measure their temperatures in real time. Therefore, the specially designed HSMS can be used to measure the DSSB, as well as the effect of working temperature on the DSSB. In addition, a standard loading rod is installed at the output end of the HSMS in a similar manner to the installation of a cutter, which can be used for radial force loading and external rotor deformation displacement measurement.

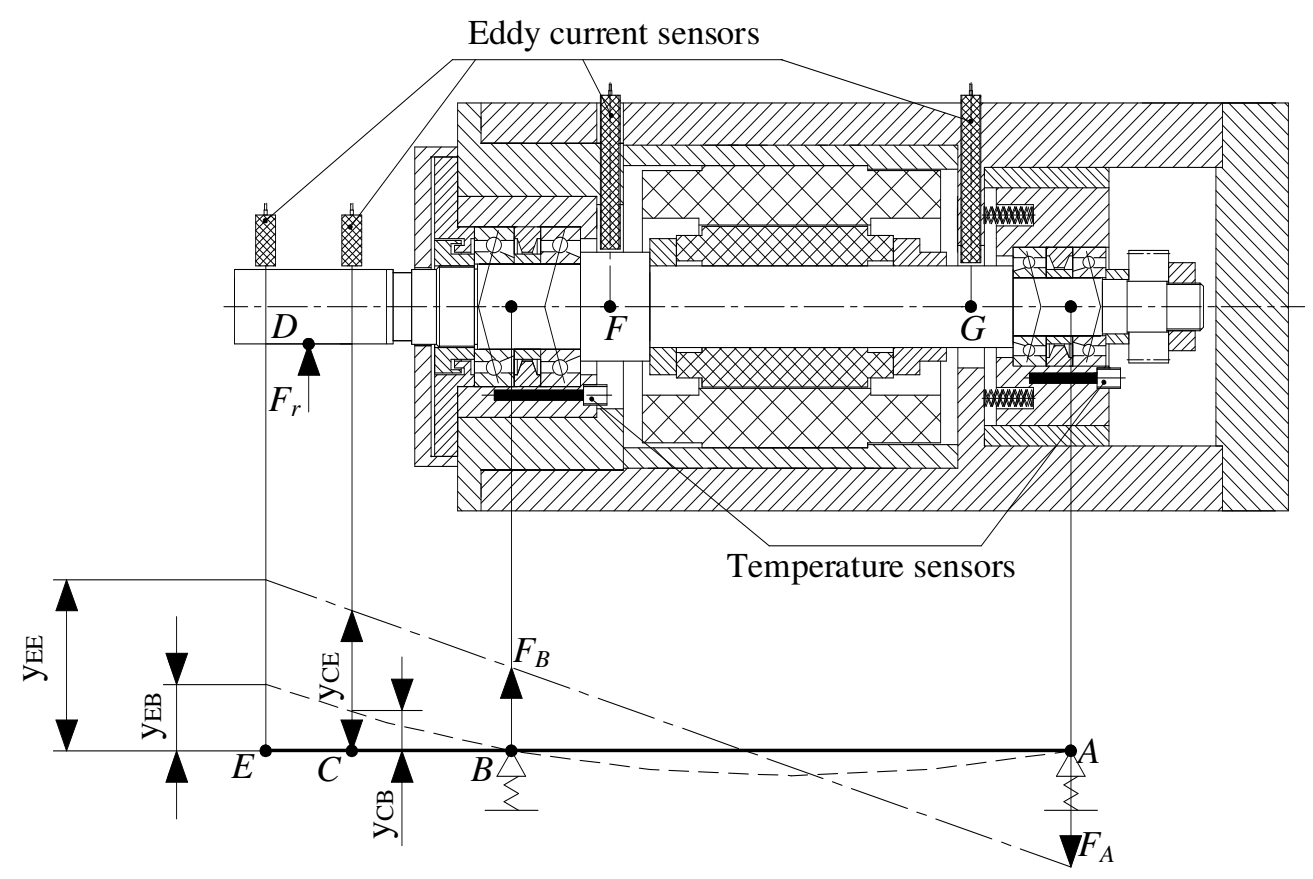

Fig 1 Structure and equivalent model of the specially designed HSMS

To indirectly analyse the DSSB by measuring the loading force and deformation displacement of the rotor, an equivalent model of an HSMS needs to be established, as shown in Figure 1. The support reaction point of the single-row angular contact ball bearings is the pressure centre of the bearing ${ }^{15}$. The pressure centre of the 
double-row angular contact ball bearings is located at the midpoint of the pressure centre of the two single-row bearings. The front and rear bearings of the experimental HSMS can be regarded as a double-row bearing, so the supporting reaction points of the front/rear bearings of the experimental HSMS can be illustrated as points A and point $B$ in Figure 1, which are at the midpoint of the pressure centres of the two single-row bearings. The position where the radial force acts is named point $\mathrm{D}$. The positions measured by the four eddy current sensors are named points $\mathrm{C}, \mathrm{E}, \mathrm{F}$ and $\mathrm{G}$.

As shown in Figure 1, segments $\mathrm{AB}$ and $\mathrm{BE}$ in the equivalent model are beam elements and the front and rear bearings are simplified into a spring. The stiffnesses of the bearings are represented by the stiffness of the springs. The dotted line represents the deflection curve of the rotor under the action of radial load $F_{r}$. At this time, it is assumed that the support bearing is rigid and there is no radial displacement deformation ${ }^{16}$ and the bending deformations at points $\mathrm{C}$ and $\mathrm{E}$ are represented by $y_{\mathrm{CB}}$ and $\mathrm{y}_{\mathrm{EB}}$, respectively. The dot-dash line indicates the displacement curve of the rotor due to the elastic support of the bearings under the action of the radial force $F_{r}$. At this time, it is assumed that the rotor is rigid and there is no bending deformation ${ }^{16}$, and the displacements at points $\mathrm{C}$ and $\mathrm{E}$ are represented by $y_{\mathrm{CE}}$ and $\mathrm{y}_{\mathrm{EE}}$, respectively.

\subsection{Analysis method of the DSSB}

From the static equilibrium conditions, the support reaction forces at support points A and B can be calculated as:

$$
\begin{gathered}
F_{A}=\frac{l_{B D}}{l_{A B}} F_{r} \\
F_{B}=\left(1+\frac{l_{B D}}{l_{A B}}\right) F_{r}
\end{gathered}
$$

where $l_{i j}$ is the distance between support points $i$ and $j$ in the equivalent model of the HSMS (mm).

Variables $\delta_{A}$ and $\delta_{B}$ are the contact deformation displacements at support points A and B. Variables $\delta_{A}$ and $\delta_{B}$ can be approximately equal to the deformation displacement of points $\mathrm{F}$ and $\mathrm{G}$, or their values can be obtained by indirect analysis based on the deformation displacement of points $\mathrm{C}$ and $\mathrm{E}$. Based on the material mechanics theory, from the deflection curve of the rotor under the action of external force $F_{r}$, the bending deformations at point $\mathrm{C}\left(y_{C B}\right)$ and point $\mathrm{E}\left(y_{E B}\right)$ are:

$$
\begin{aligned}
& y_{C B}=\frac{F_{r} l_{B C}{ }^{2}}{6 E J}\left(3 l_{B D}-l_{B C}\right) \\
& y_{E B}=\frac{F_{r} l_{B D}^{2}}{6 E J}\left(3 l_{B E}-l_{B D}\right)
\end{aligned}
$$

where $E(\mathrm{MPa})$ is the elastic modulus of the rotor; and $J\left(\mathrm{~mm}^{4}\right)$ is the equivalent moment of inertia of the rotor, 
where:

$$
J=\frac{\pi d_{v}^{4}}{64}
$$

where $d_{v}(\mathrm{~mm})$ is the equivalent diameter of the step shaft equivalent to the optical shaft, which can be calculated by the following formula ${ }^{15}$ :

$$
d_{v}=\sqrt[4]{\frac{L}{\sum_{i=0}^{n} \frac{l_{i}}{d_{i}^{4}}}}
$$

where $d_{i}(\mathrm{~mm})$ and $l_{i}(\mathrm{~mm})$ are the diameter and length of the $i^{\text {th }}$ stepped shaft, respectively, $L(\mathrm{~mm})$ is the total length of the stepped shaft, and $n$ is the number of steps of the stepped shaft.

The deformation displacements of point $\mathrm{C}\left(y_{C E}\right)$ and point $\mathrm{E}\left(y_{E E}\right)$ due to the elastic support of the bearings can be calculated from the geometric relationship of the equivalent model of the HSMS:

$$
\begin{gathered}
y_{C E}=\frac{l_{A C}}{l_{A B}}\left(\delta_{A}+\delta_{B}\right)-\delta_{A} \\
y_{E E}=\frac{l_{A E}}{l_{A B}}\left(\delta_{A}+\delta_{B}\right)-\delta_{A}
\end{gathered}
$$

The total deformation displacements at point $\mathrm{C}\left(y_{C T}\right)$ and point $\mathrm{E}\left(y_{E T}\right)$, as measured directly by the eddy current sensors, are:

$$
\begin{aligned}
& y_{C T}=y_{C B}+y_{C E} \\
& y_{E T}=y_{E B}+y_{E E}
\end{aligned}
$$

Variables $y_{C E}$ and $y_{E E}$ can be calculated from Equations (3), (4), (9) and (10), then $y_{C E}$ and $y_{E E}$ can be substituted into Formulas (7) and (8) to obtain the contact deformation displacements $\delta_{A}$ and $\delta_{B}$. The radial loading forces $F_{A}$ and $F_{B}$ at points A and B can be calculated from Equations (1) and (2). According to the definition of stiffness, the DSSB is:

$$
\begin{gathered}
K_{A}=\frac{d F_{A}}{d \delta_{A}} \\
K_{B}=\frac{d F_{B}}{d \delta_{B}}
\end{gathered}
$$

The above method of analysing the DSSB by measuring the deformation displacements at two points on the external loading rod of the HSMS is called the external measurement method (EMM) in this article. Because there is no need to modify the structure and design of the HSMS, the biggest advantage of EMM is its versatility. To 
verify the effectiveness of the EMM, a special HSMS was designed (as shown in Figure 1). The eddy current sensors installed near the front and rear bearings can directly measure the contact deformation displacements $\delta_{A}$ and $\delta_{B}$ of the front and rear bearings, and are used to directly obtain the DSSB. This method is called the internal measurement method (IMM) in this article. The biggest advantage of IMM is that the measured DSSB is more accurate than that of EMM.

\section{Experimental setup}

Due to the HSMS's structural characteristics and extremely high rotational speed, it is difficult to achieve dynamic loading of it. In this paper, a novel contact loading device was designed to test the rotor operating stiffness and DSSB. Figure 2 shows the structure and composition of the contact loading device, which is composed of a mechanical device and a measurement and control device. The mechanical device is mainly composed of a cylinder, floating joint, sliding pillar, sliding base and four rolling bearings. The sliding pillar and the sliding base fixed on the experimental rig constitute a sliding pair. The sliding pillar is pushed up by the cylinder, so that the outer rings of the rolling bearings installed on the sliding base contact the rotor of the HSMS to achieve loading. The loading principle is shown in Figure 3. By adjusting the air pressure of the cylinder, the radial loading force can be effectively regulated. To avoid mechanical interference caused by coaxiality errors during installation, a floating joint is used to connect the cylinder and force sensor. Oil-air lubrication not only has a lubricating effect but also takes away much heat via the air, which is used to lubricate and cool the contact position between the rolling bearings and the loading rod.

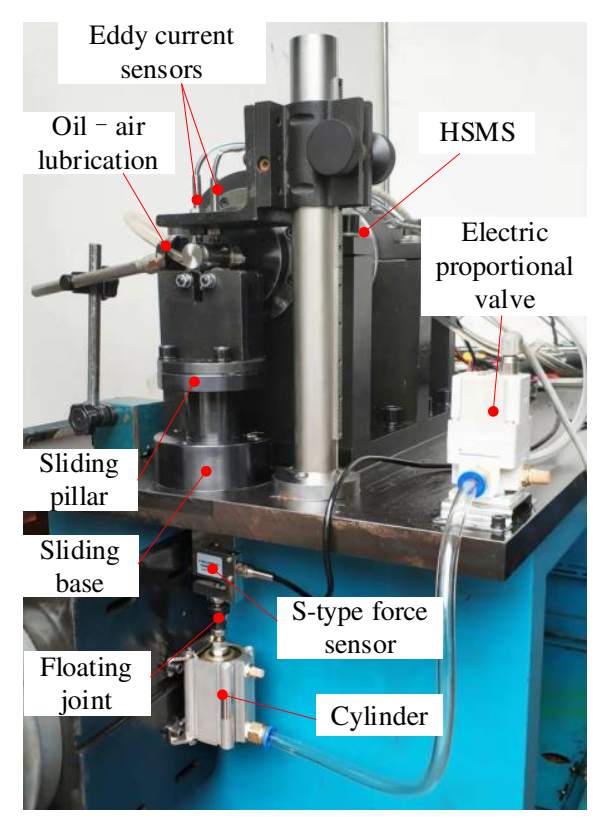

Fig 2 Test system for rotor operating stiffness and DSSB of HSMS 


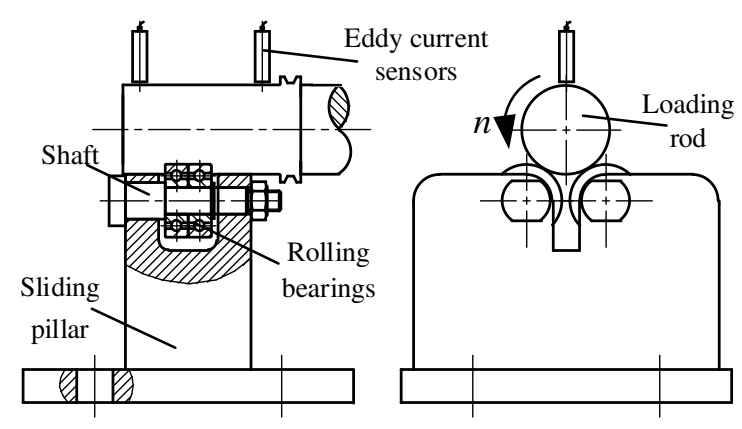

Fig 3 Schematic diagram of HSMS radial loading

The main components of the measurement and control device are an electric proportional valve, S-type force sensor, eddy current sensors and data collection device. By adjusting the analogue voltage of the electric proportional valve, the air pressure of the cylinder and the loading force can be adjusted. Four eddy current sensors are used to measure the deformation displacement of the HSMS rotor. The S-type force sensor is used to measure the loading force. The data collection device consists of an N/I Compact DAQ chassis (cDAQ-9174) and computer software. The N/I 9239 module can measure the signal of the sensors simultaneously. The N/I 9263 module can control the analog voltage of the electric proportional valve. The computer software is compiled in LABVIEW language and provides an interface for loading force control and the display, analysis, storage and printing of sensor signals. Finally, the relationship between loading force and deformation displacement is obtained in the computer software, and the rotor operating stiffness and DSSB under high-speed rotation are effectively measured and analysed.

There are some advantages to the HSMS dynamic support stiffness testing system proposed in this paper: 1) Compared with the traditional contact loading techniques described in the Introduction, this test system has lower installation accuracy requirements and has little effect on the dynamic balance of the HSMS rotor, so the applicable speed is higher. Compared with non-contact loading systems, the structure of the test system is simple and the loading force is high and stable. 2) Using at least two eddy current sensors to measure the deformation displacement of the HSMS rotor combined with the experimental data analysis method described in Section 2.2, the DSSB can be quantitatively measured. 3) The loading force can be conveniently and accurately controlled by the electric proportional valve. The loading force and deformation displacement can be measured synchronously in real-time. The measurement accuracy of the testing system is high. 4) The loading rod is installed on the HSMS in a similar way to a cutter, which makes it convenient for testing different types of HSMSs. Hence, the testing system has high versatility.

\section{Experimental process and results}

\subsection{Experimental process}

The test system in Figure 2 was used to test the DSSB of the experimental HSMS. Before the experiment, the 
minimum proportional valve voltage $U_{0}$ required to bring the loading device into contact with the loading rod was determined by a static loading experiment to be $0.6 \mathrm{~V}$. This avoided impact collisions between the loading device and loading rod during the experiment. The maximum proportional valve voltage $U_{\max }$ of the proportional valve was set to $3.5 \mathrm{~V}$. The corresponding loading forces of the front and rear bearings were 150-450 N and 50-150 N, respectively. The effect of radial forces in the range of $0-30,000 \mathrm{rpm}$ on the DSSB was tested at $6000 \mathrm{rpm}$ intervals. After the HSMS ran stably at the experimental speed, it was loaded and the loading force and deformation displacement at four positions were measured simultaneously. The proportional valve voltage was gradually increased $(0.1 \mathrm{~V} / \mathrm{s})$ from $U_{0}$ to $U_{\max }$. The proportional valve voltage was maintained at $U_{\max }$ for about $15 \mathrm{~s}$ and then gradually decreased $(-0.1 \mathrm{~V} / \mathrm{s})$ to $U_{0}$. The above process was repeated 2-3 times to verify the repeatability of the experiment. The original experimental data of the HSMS at a speed of $24,000 \mathrm{rpm}$ is shown in Figure 4. It shows that under the same loading force, the deformation displacement of the measuring points in the EMM was much larger than that in the IMM, which shows that the bending deformation displacement of the loading rod due to the cantilever beam cannot be ignored.
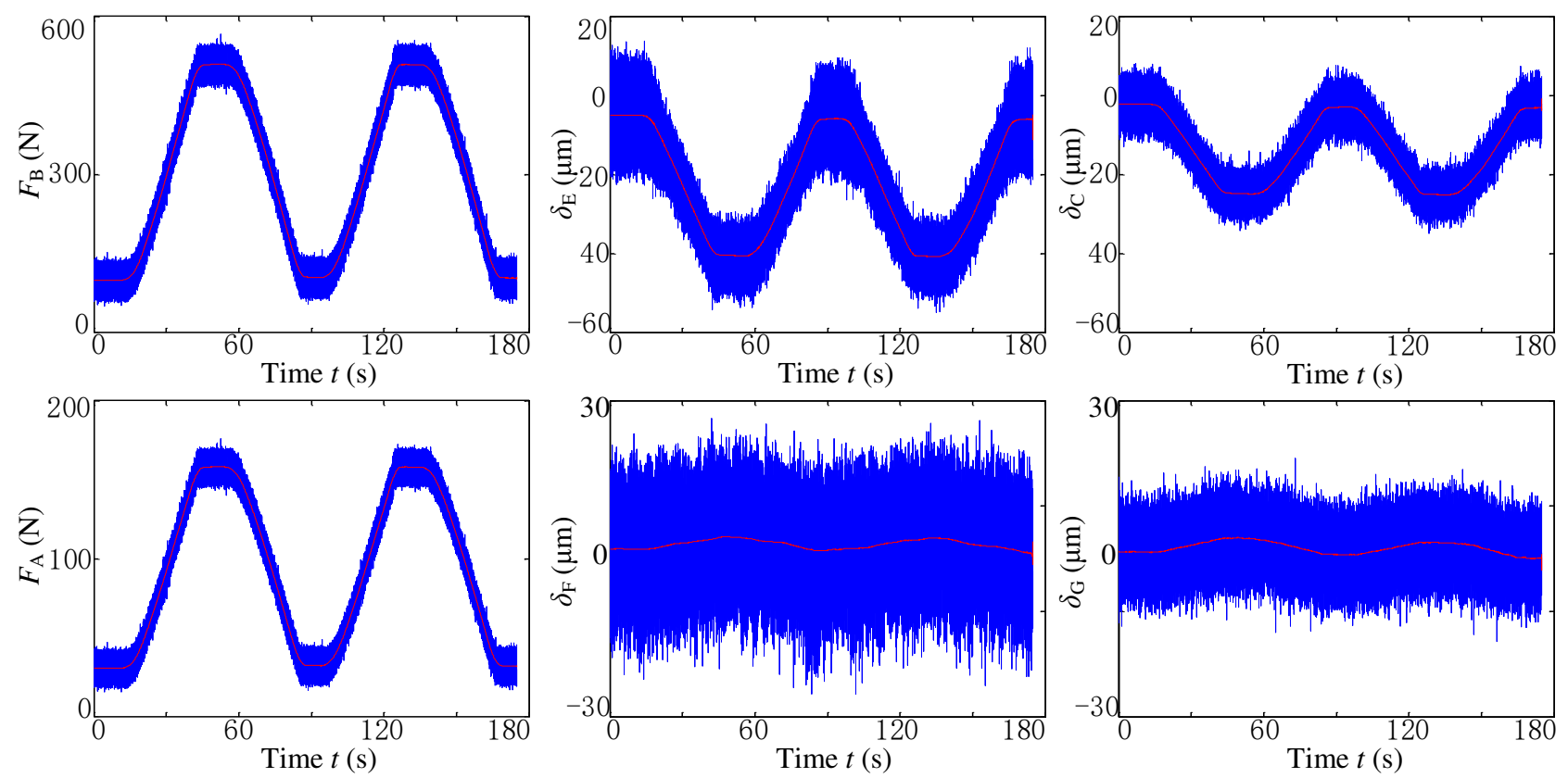

Fig 4. Original experimental data of loading force and deformation displacement: $F_{A}$ and $F_{B}=$ loading forces of support points $\mathrm{A}$ and $\mathrm{B}$ in the equivalent model; $\delta_{C}, \delta_{E}, \delta_{F}$, and $\delta_{G}=$ deformation displacements of points $\mathrm{C}, \mathrm{E}, \mathrm{F}$, and $\mathrm{G}$, respectively, in the equivalent model ( $n=24,000 \mathrm{rpm})$.

Using the EMM and IMM described in Section 2.2 to analyse the experimental results, the relationship between the loading force and deformation displacement of the front/rear bearings at 24,000 rpm was derived (Figure 5). The original measured data (blue curves) was corrected by low-pass filtering (green curves); then, the one-to-one correspondence between loading force and deformation displacement (red curve) was obtained by 
polynomial fitting. According to Figure 5, the radial deformation displacement $\delta_{r}$ of the front/rear bearings increases with increases in the radial force $F_{r}$. According to Equations (11) and (12), we can verify that the DSSB can be obtained by deducing the radial force $F_{r}$ to the deformation displacement $\delta_{r}$. That is, the polynomial model (red curve) is derived to obtain the DSSB.
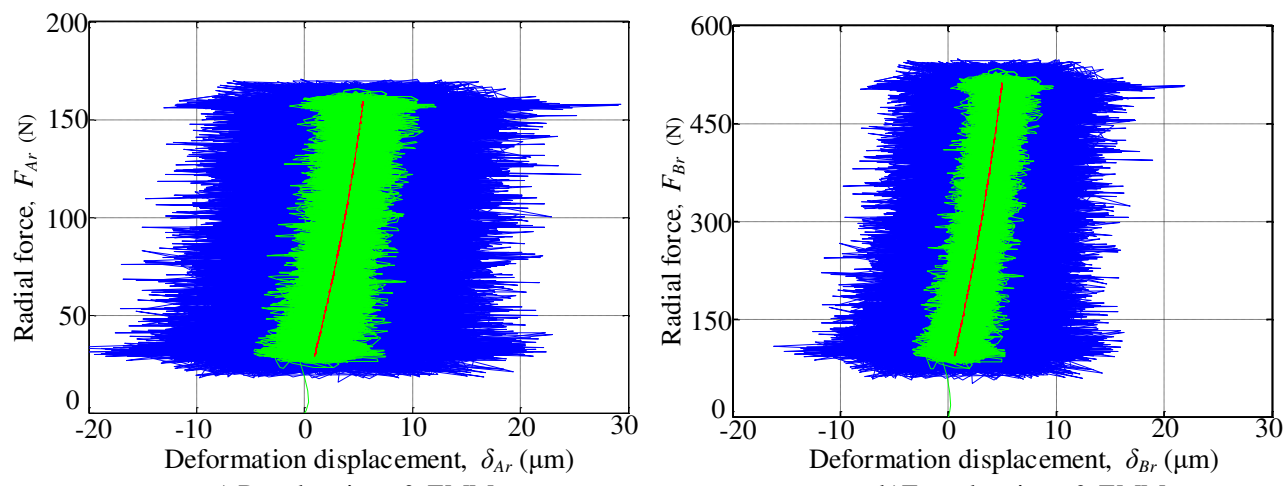

a) Rear bearings \& EMM

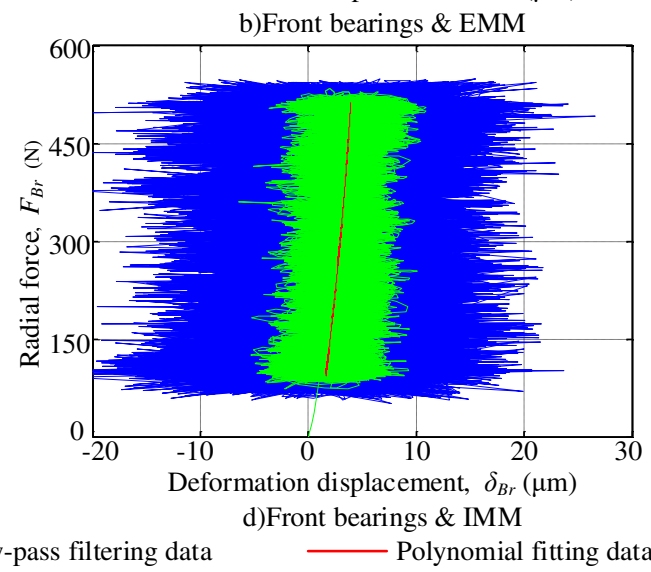

Fig 5 Radial force $F_{r}$ vs deformation displacement $\delta_{r}$ of the front/rear bearings measured by EMM and IMM ( $n=$ $24,000 \mathrm{rpm})$.

\subsection{Effect of radial force on the DSSB}

Figure 6 shows the experimental results regarding the effect of the radial force on the DSSB, including analyses by EMM and IMM. It can be seen from Figure 6 that, first, as the radial force $F_{r}$ increases, the DSSB $K_{r}$ increases nonlinearly. This is mainly because the radial force $F_{r}$ makes the contact deformation of the half-turn rolling elements in the radial force direction increase, and the contact deformation of the other half-turn rolling elements decreases, but the overall resistance to deformation of the contact surface is increased ${ }^{17}$. Second, the trends of DSSB obtained by the EMM and IMM are consistent, but the EMM measurements are significantly less than those of IMM. This is mainly due to the tapered connection gap between the loading rod and the rotor, which makes the measured deformation displacement $\delta_{r}$ of the loading rod larger in the EMM. Third, the stiffness of the front bearings $(\mathrm{B} 7005 / \mathrm{C})$ is greater than that of the rear bearings $(\mathrm{B} 7003 / \mathrm{C})$, which is mainly due to their larger size. Fourth, the experimental results of 2-3 loading and unloading cycles (as shown in Figure 4) show that both the 
EMM and IMM have good repeatability.

Although the EMM estimates the measured DSSB to be lower due to the tapered connection gap, it still has certain application value due to its convenient installation and lack of need to modify the structure and design of the HSMS. Moreover, the rotor operating stiffness measured by the EMM can better reflect the true anti-deformation ability of the HSMS. In contrast, the IMM can more accurately measure the DSSB by measuring the deformation displacement of the internal rotor, which provides a new way to experimentally verify the theoretical bearing stiffness models.
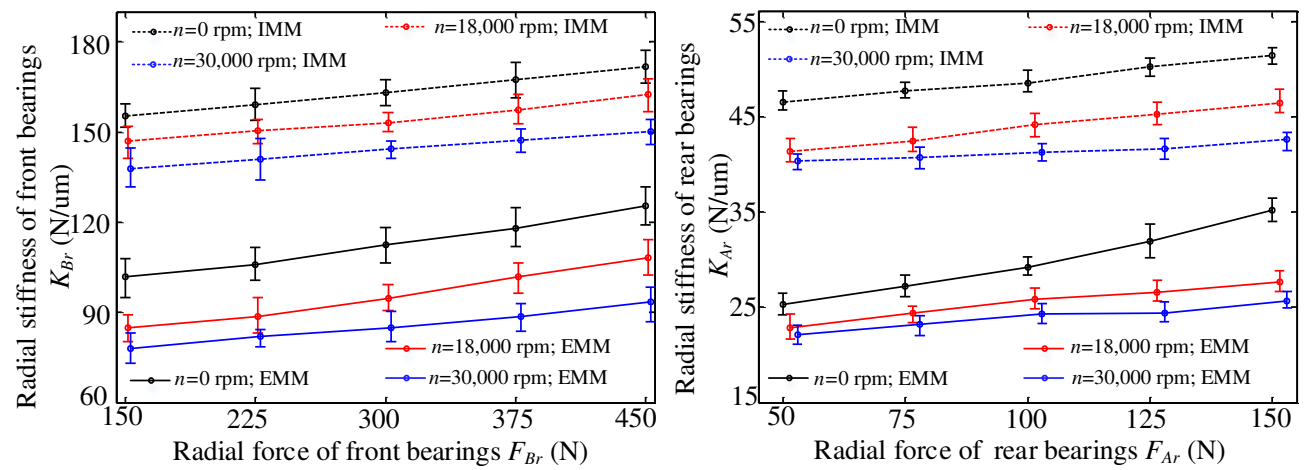

Fig 6 Effect of radial force on the radial stiffnesses of the front (left) and rear (right) HSMS bearings

\subsection{Effect of speed on the DSSB}

The influence of speed on the DSSB is shown in Figure 7. The experimental results show that the experimental device and schemes proposed in this paper could effectively measure the DSSB at speeds of up to $30,000 \mathrm{rpm}$. It can be seen from Figure 7 that as the speed increases, the DSSB tend to decrease. This is mainly due to the fact that as the speed increases, the centrifugal force and gyroscopic moment push the rolling elements outward, resulting in a reduction in the contact area of the bearing rolling elements and inner ring, which reduces the bearing stiffness ${ }^{18}$. The rotor operating stiffness of the HSMS mainly depends on its DSSB and so will also decrease with increasing speed ${ }^{19}$.
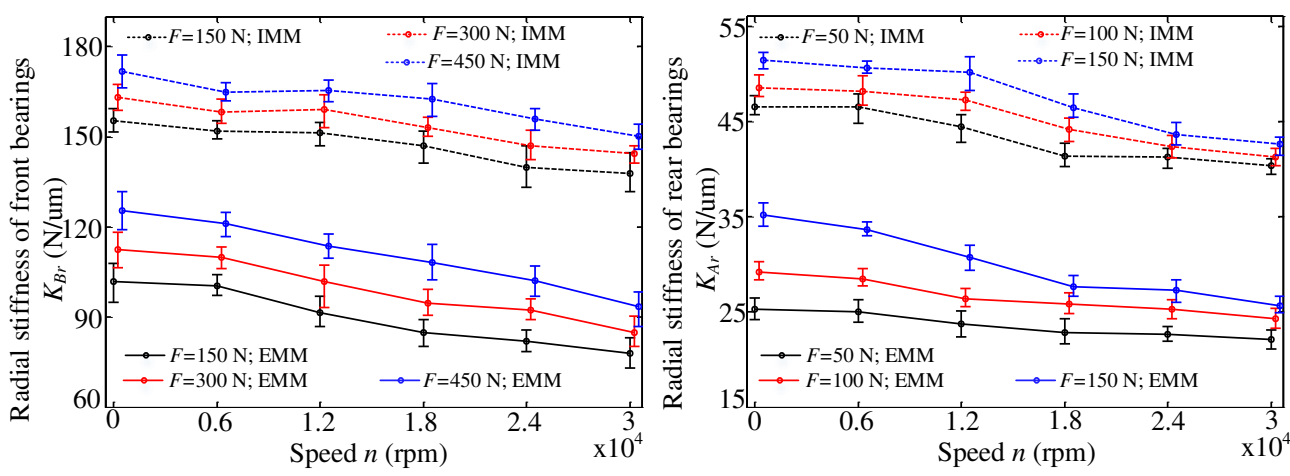

Fig 7 Effect of speed on the radial stiffnesses of the front (left) and rear (right) HSMS bearings 


\subsection{Effect of working temperature on the DSSB}

The temperature increases of the HSMS are more serious at high speed, so it is necessary to study the influence of working temperature on the DSSB. The working temperature of the HSMS was varied by controlling the flow of cooling water. During the experiments, the cooling water was pumped at maximum, half and zero speeds. The working temperatures of the front/rear bearings were measured by built-in temperature sensors (as shown in Figure 1). When the working temperatures of the bearings were basically stable, the EMM and IMM were used to measure the DSSB during a loading process. The average temperatures of the front/rear bearings during the loading process were taken as their working temperature. The influence of working temperature on the DSSB at an experimental HSMS speed of 24,000 rpm was obtained (Figure 8). Figure 8 shows that as the working temperature increases, the DSSB increase. This is mainly due to thermal expansion of the bearings due to the temperature rise, which made the contact between the rolling elements and the inner/outer rings closer and, ultimately, led to an increase in the $\mathrm{DSSB}^{13}$. Although a higher operating temperature helps to increase the DSSB of the HSMS, it will seriously deteriorate the lubrication conditions and increase the contact load of the bearings, which will eventually lead to damage or wear of the HSMS ${ }^{20}$. Therefore, it is very necessary to use circulating water to cool the HSMS rotor and bearings and the influence of temperature increases on the dynamic performance of HSMS cannot be ignored.
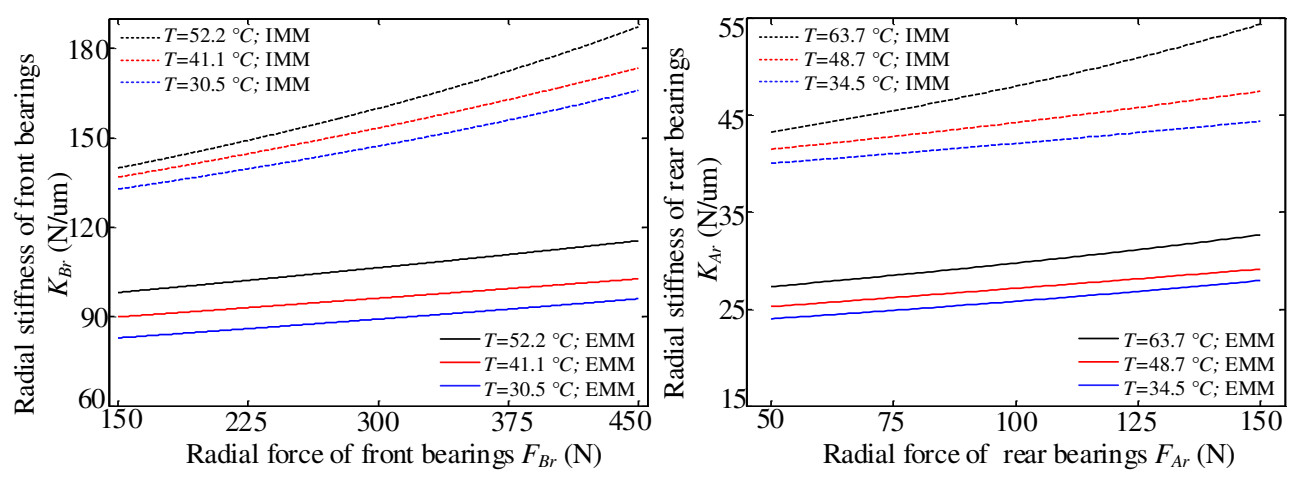

Fig 8 Effect of working temperature on the radial stiffnesses of the front (left) and rear (right) HSMS bearings

\section{Conclusions}

In this paper, a new method of dynamically loading a high-speed motorized spindle (HSMS) was proposed. Two experimental schemes for measuring the dynamic support stiffnesses of the front/rear bearings (DSSB) were studied. The influence of working-condition parameters on the DSSB was tested on the built test system. We obtained the following conclusions:

1) The experiments show that the dynamic loading device could load the HSMS smoothly at speeds is as high as 30,000 rpm, which solves the loading problem in HSMS stiffness testing.

2) Because the tapered connection gap between the loading rod and rotor decreases the stiffness, the DSSB measured by the external measurement method (EMM) - where the DSSB is an indirect measurement made by 
analysing the deformation displacements of two points on the external loading rod of the HSMS—was relatively small. However, because the EMM does not need to modify the structural design of the HSMS, it has high versatility and application value.

3) The internal measurement method (IMM) — where the DSSB is directly measured by eddy current sensors installed near the front/rear bearings — can more accurately measure the DSSB. This verifies the validity and correctness of the EMM and provides an experimental basis for the verification of theoretical bearing stiffness models.

4) The experimental results show that both the EMM and IMM have high repeatability. The DSSB decreases with speed and increases with radial force and working temperature.

\section{Funding}

This work was supported by the National Key R\&D Program of China (grant number 2018YFB2000500), the Scientific and Technological Research Program of Chongqing Municipal Education Commission (grant number KJQN201900815) and the Key Projects of Strategic Scientific and Technological Innovation Cooperation of National Key R\&D Program of China (grant number 2020YFE0201000).

\section{Declaration of conflicting interests}

The author(s) declared no potential conflicts of interest with respect to the research, authorship, and/or publication of this article.

\section{References}

1. Tian S L, Chen X A, He Y, et al. A dynamic loading system for high-speed motorized spindle with magnetorheological fluid. Journal of Intelligent Material Systems and Structures 2018; 29: 2754-2765.

2. Cheng H C, Zhang Y M, Lu W J, et al. Research on mechanical characteristics of fault-free bearings based on centrifugal force and gyroscopic moment. Archive of Applied Mechanics 2020; 90: 2157-2184.

3. Chen C, Chen F, Ye Y F, et al. Design of accelerated reliability test for $\mathrm{CNC}$ motorized spindle based on vibration signal. In: MATEC Web of Conferences 2016, p.02001. EDP Sciences.

4. Albrecht A, Park S S, Altintas Y, et al. High frequency bandwidth cutting force measurement in milling using capacitance displacement sensors. International Journal of Machine Tools and Manufacture 2005; 45: 993-1008.

5. Ozturk E, Kumar U, Turner S, et al. Investigation of spindle bearing preload on dynamics and stability limit in milling. CIRP Annals - Manufacturing Technology 2012; 61: 343-346.

6. Wang X P, Guo Y Z and Chen T N. Measurement Research of Motorized Spindle Dynamic Stiffness under High Speed Rotating. Shock and Vibration 2015; 2015: 1-11.

7. Matsubara A, Yamazaki $T$ and Ikenaga S. Non-contact measurement of spindle stiffness by using magnetic loading device. International Journal of Machine Tools Manufacture 2013; 71: 20-25.

8. Feng M, Zhao Y L, Yang W, et al. The Development of Non-Contact Gas-Loading System for Stiffness Measurement of High Speed Spindles. Machinery Design \& Manufacture 2013; 6: 102-105. (Chinese)

9. Lei C L, Li F H, Gong B R, et al. An Integrated Model to Characterize Comprehensive Stiffness of Angular Contact Ball Bearings. Math Probl Eng 2020; 2020: 1-12. 
10. Yang $\mathrm{Z} \mathrm{H}$, Li B T and Yu T X. Influence of structural parameters and tolerance on stiffness of high-speed ball bearings. International Journal of Precision Engineering Manufacturing 2016; 17: 1493-1501.

11. Gunduz A, Dreyer J T and Singh R. Effect of bearing preloads on the modal characteristics of a shaft-bearing assembly: Experiments on double row angular contact ball bearings. Mechanical Systems Signal Processing 2012; 31: 176-195.

12. Hu T, Yin G F and Sun M N. Model based research of dynamic performance of shaft-bearing system in high-speed field. Shock Vib 2014; 2014: 1-12.

13. Zhang $P$ and Chen $X$ A. Thermal-mechanical coupling model-based dynamical properties analysis of a motorized spindle system. Proceedings of the Institution of Mechanical Engineers, Part B: Journal of Engineering Manufacture 2016; 230: 732-743.

14. Lin S Y and Jiang S Y. Dynamic Characteristics of Motorized Spindle With Tandem Duplex Angular Contact Ball Bearings. Journal of Vibration and Acoustics 2019; 141: 061004

15. Childs P. Mechanical design. 2nd ed. London, U.K: Elsevier Butterworth Heinemann, 2004.

16. Zhao W Y, Tao J Z and Xia H. Stiffness measurement method of air bearing. Modern Manufacturing Engineering 2012; 22: 104-106. (Chinese)

17. Fang B, Zhang J H, Yan K, et al. A comprehensive study on the speed-varying stiffness of ball bearing under different load conditions. Mechanism Machine Theory 2019; 136: 1-13.

18. Yi D, Yang Y, Zhuo X, et al. An improved dynamic model for angular contact ball bearings under constant preload. Journal of the Chinese Institute of Engineers 2016; 39: 900-906.

19. Jiang S Y and Zheng S F. Dynamic design of a high-speed motorized spindle-bearing system. J Mech Design 2010; 132: 034501 .

20. Li S S, Shen Y and He Q. Study of the thermal influence on the dynamic characteristics of the motorized spindle system. Advances in Manufacturing 2016; 4: 355-362. 
Figures

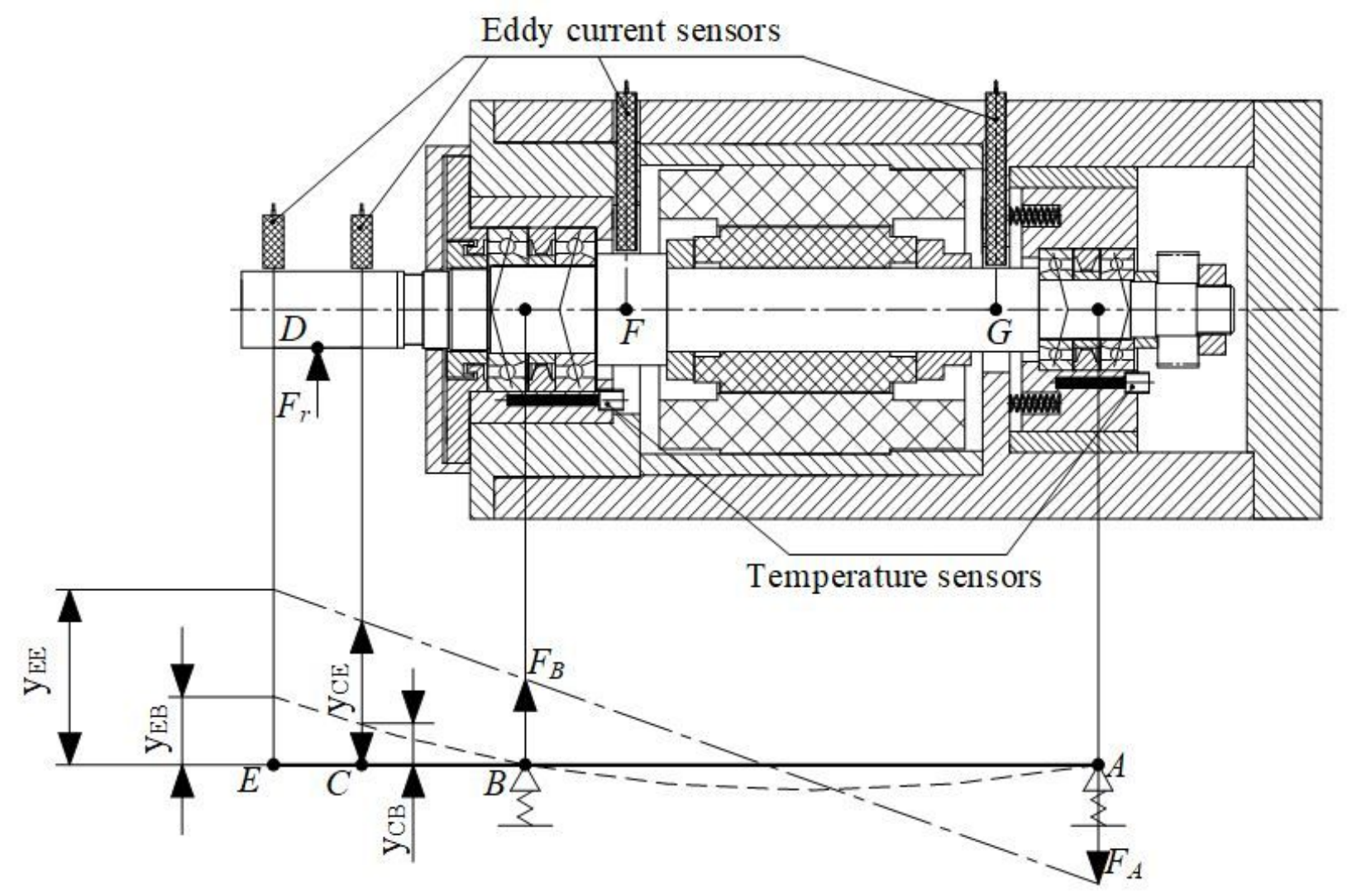

Figure 1

Structure and equivalent model of the specially designed HSMS 


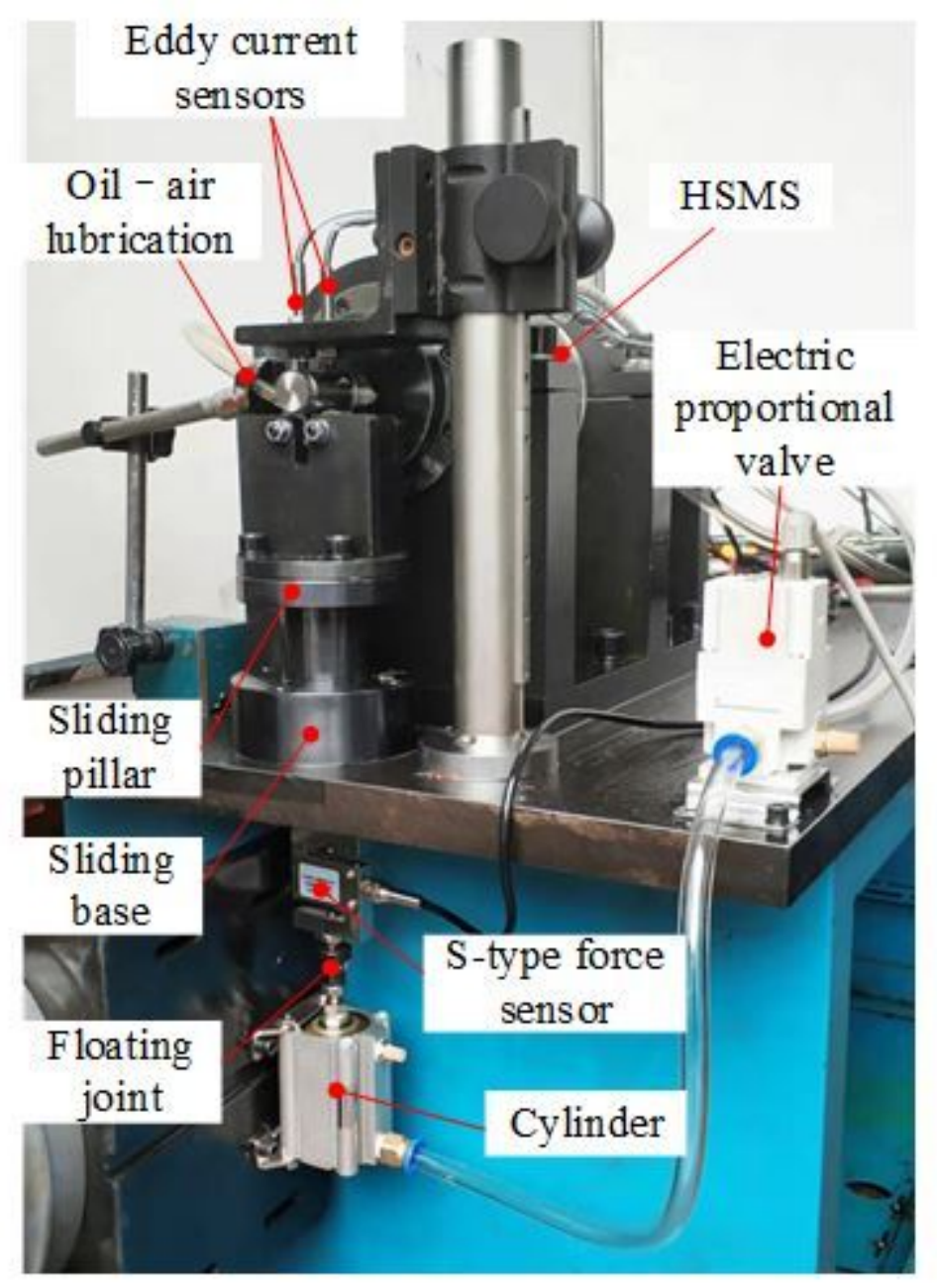

Figure 2

Test system for rotor operating stiffness and DSSB of HSMS 


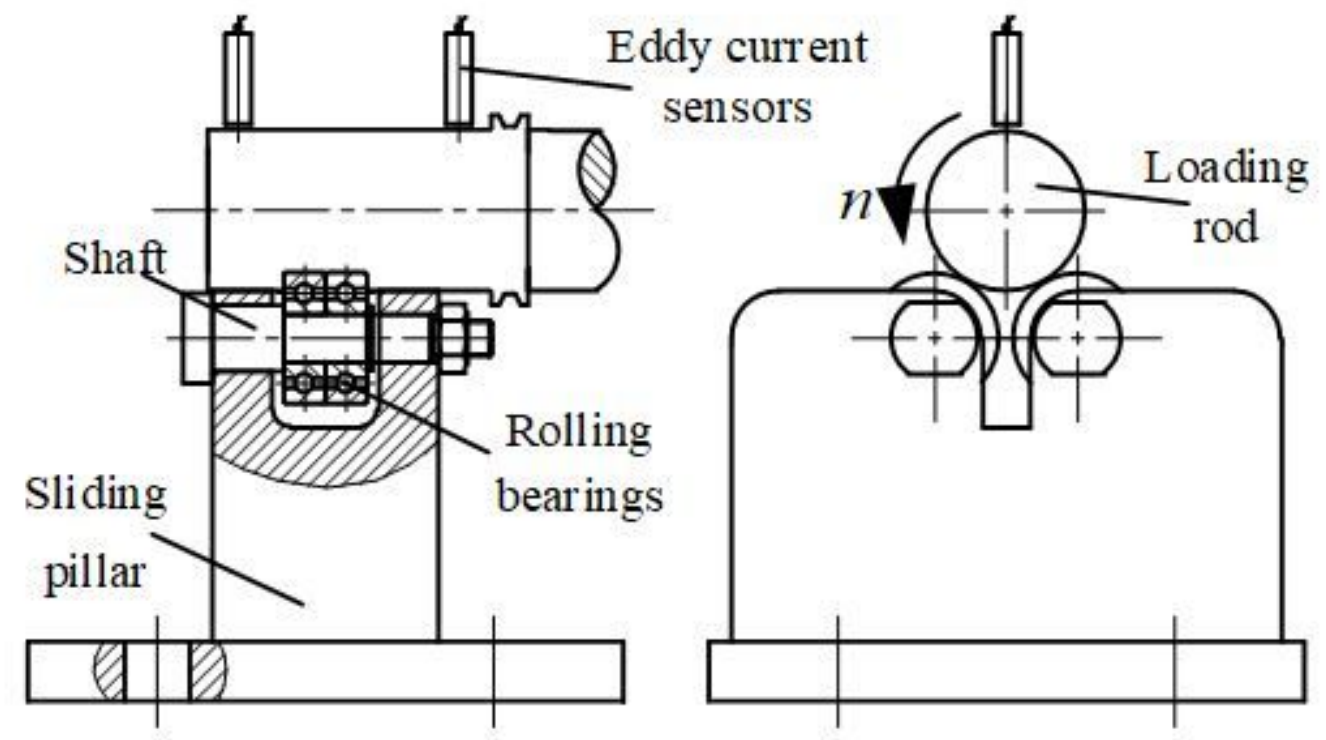

Figure 3

Schematic diagram of HSMS radial loading
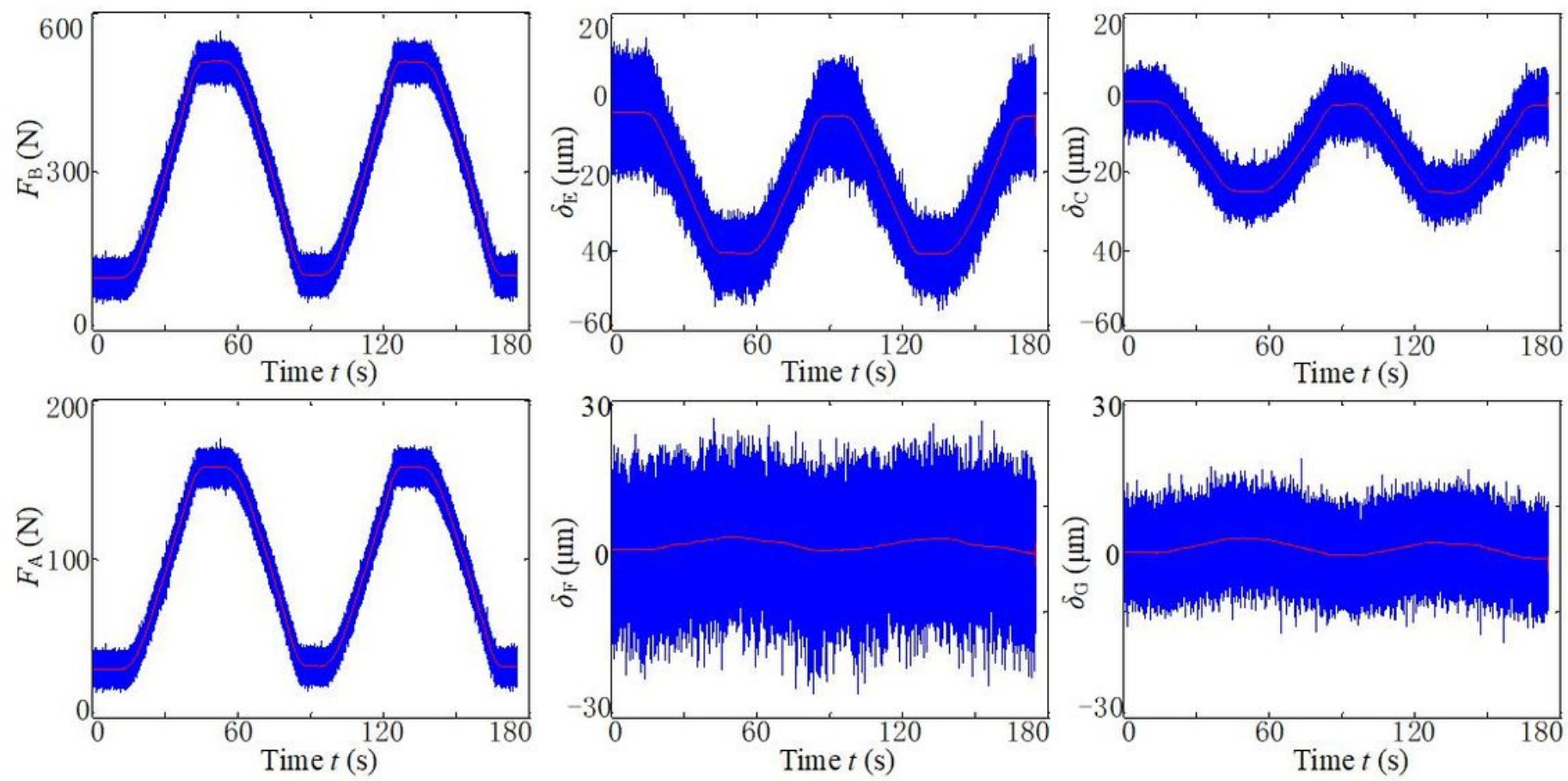

Figure 4

Original experimental data of loading force and deformation displacement: FA and FB = loading forces of support points $A$ and $B$ in the equivalent model; $\delta C, \delta E, \delta F$, and $\delta G=$ deformation displacements of points $C, E, F$, and $G$, respectively, in the equivalent model $(n=24,000 \mathrm{rpm})$. 

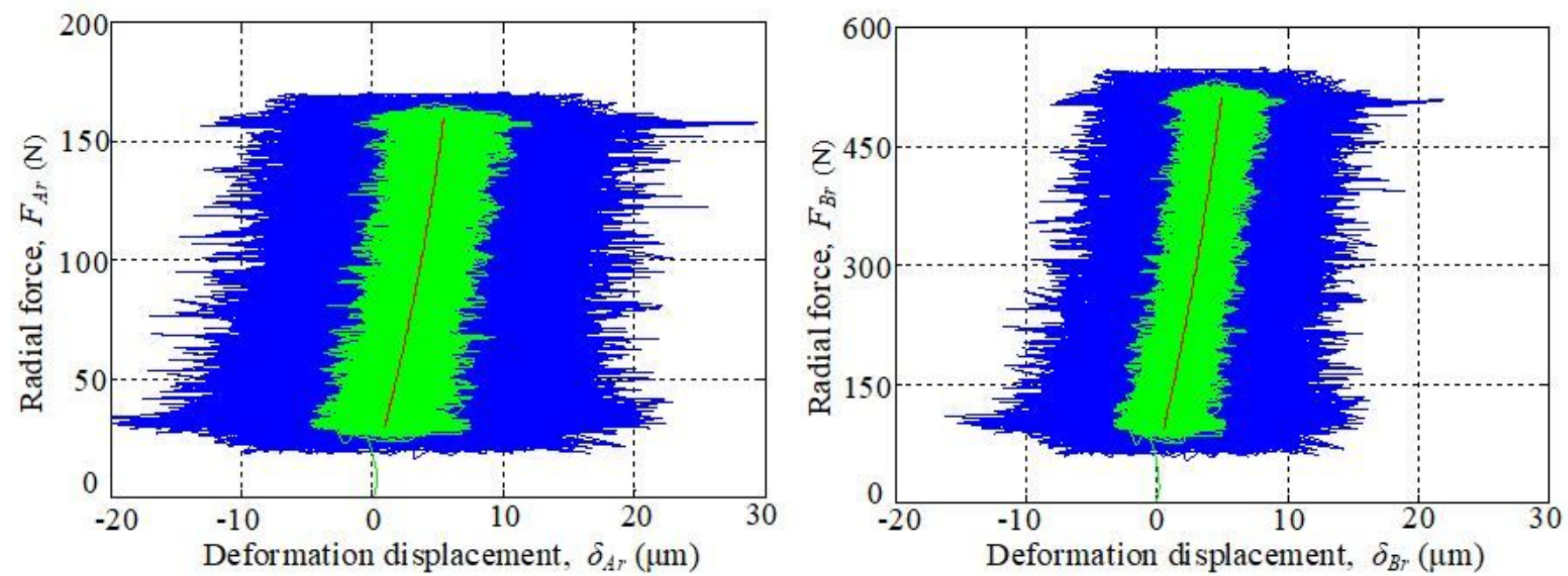

a) Rear bearings \& EMM

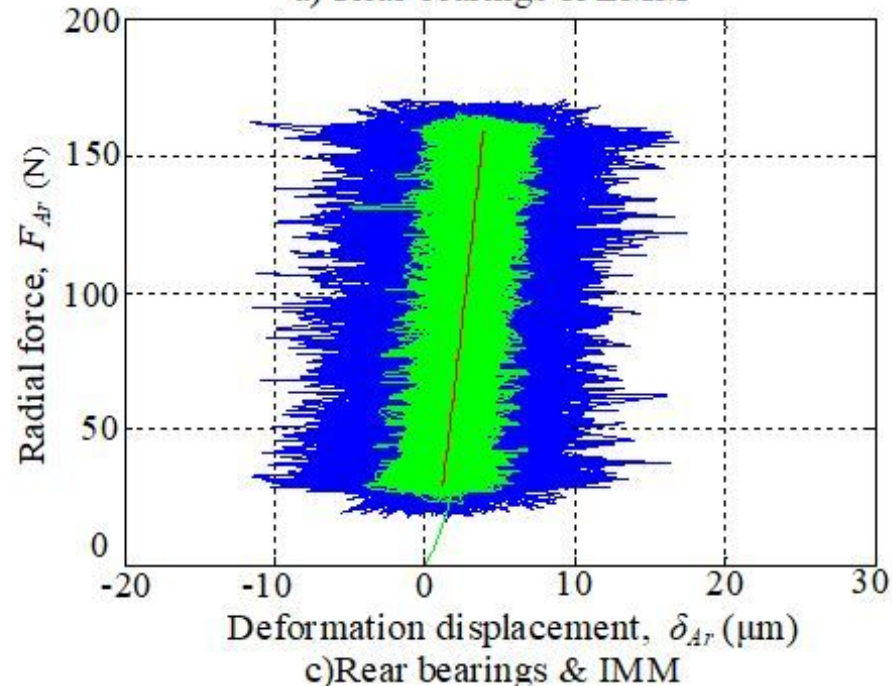

b)Front bearings \& EMM

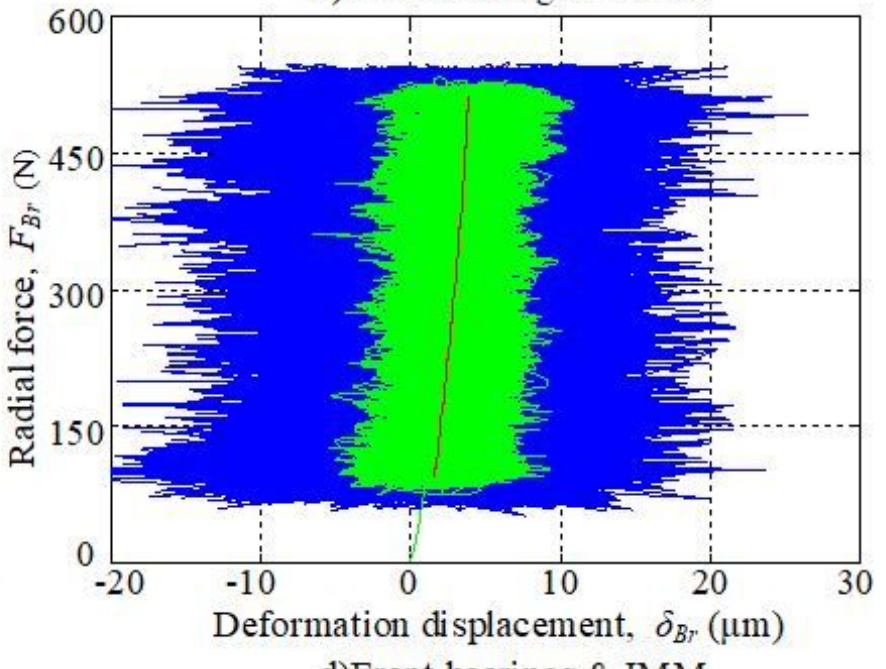

d)Front bearings \& IMM

Original measured data

Low-pass filtering data

- Polynomial fitting data

\section{Figure 5}

Radial force Fr vs deformation displacement $\delta r$ of the front/rear bearings measured by EMM and IMM ( $\mathrm{n}$ $=24,000 \mathrm{rpm})$. 

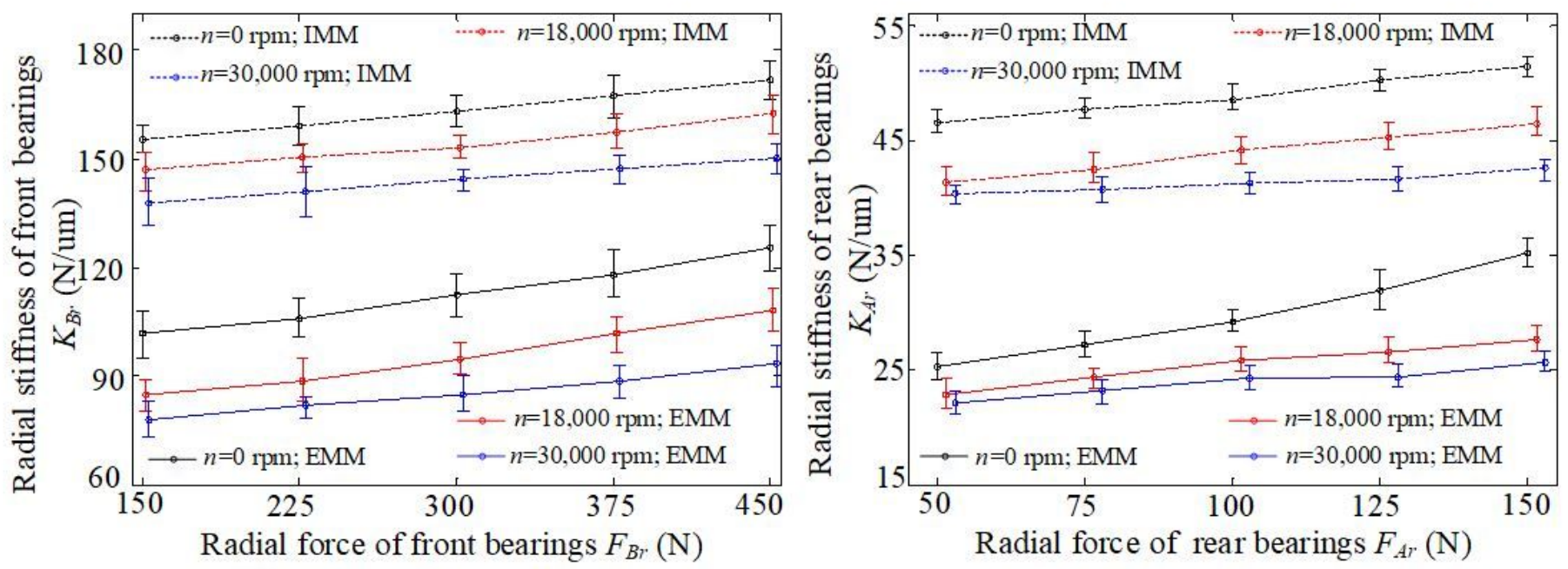

Figure 6

Effect of radial force on the radial stiffnesses of the front (left) and rear (right) HSMS bearings
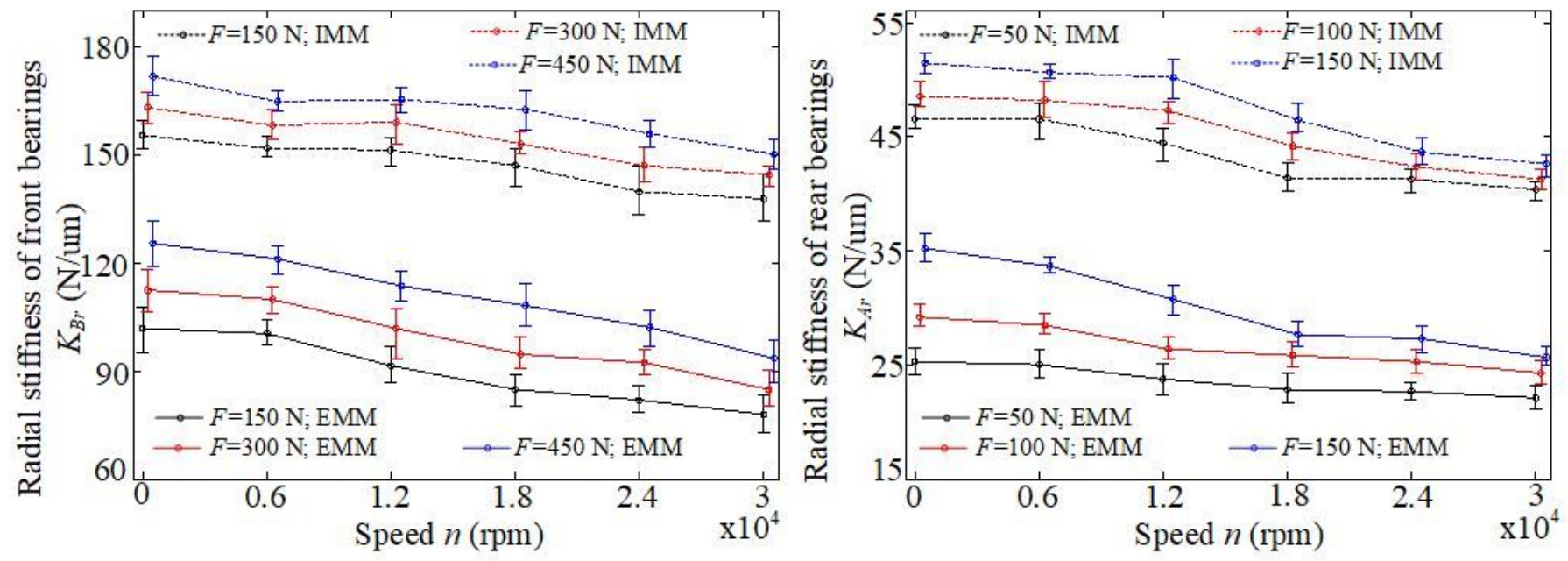

Figure 7

Effect of speed on the radial stiffnesses of the front (left) and rear (right) HSMS bearings 

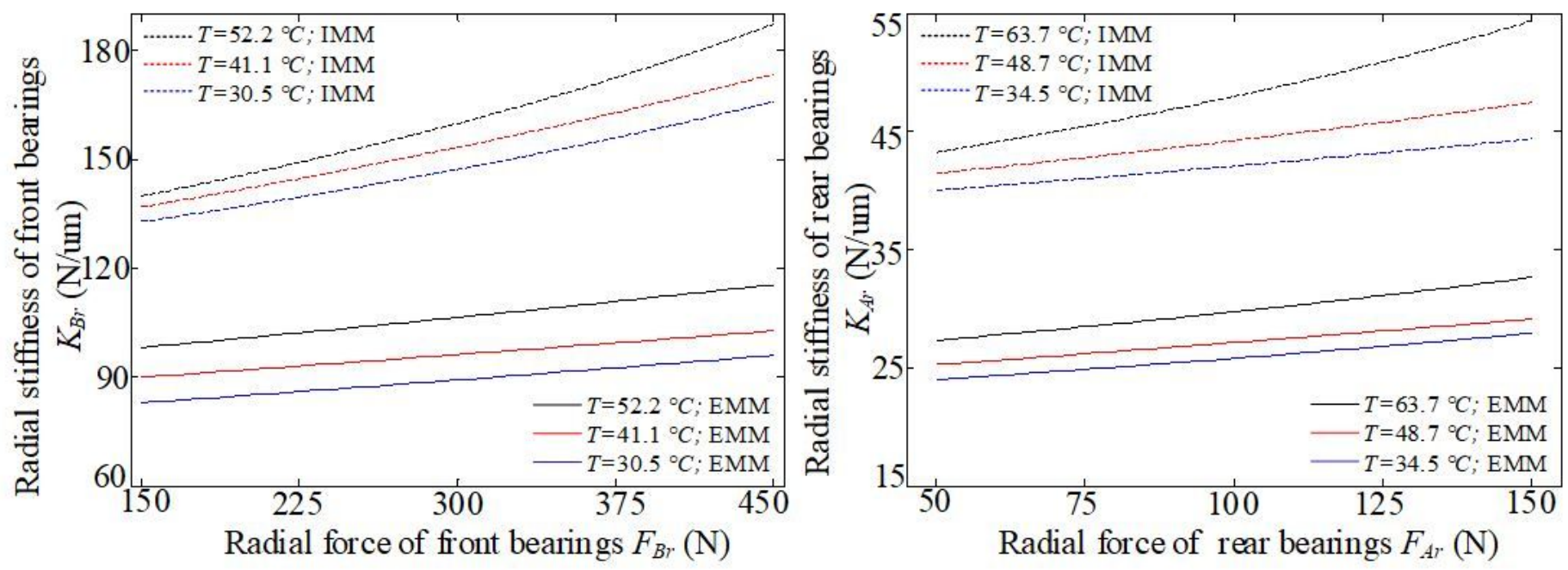

Figure 8

Effect of working temperature on the radial stiffnesses of the front (left) and rear (right) HSMS bearings 